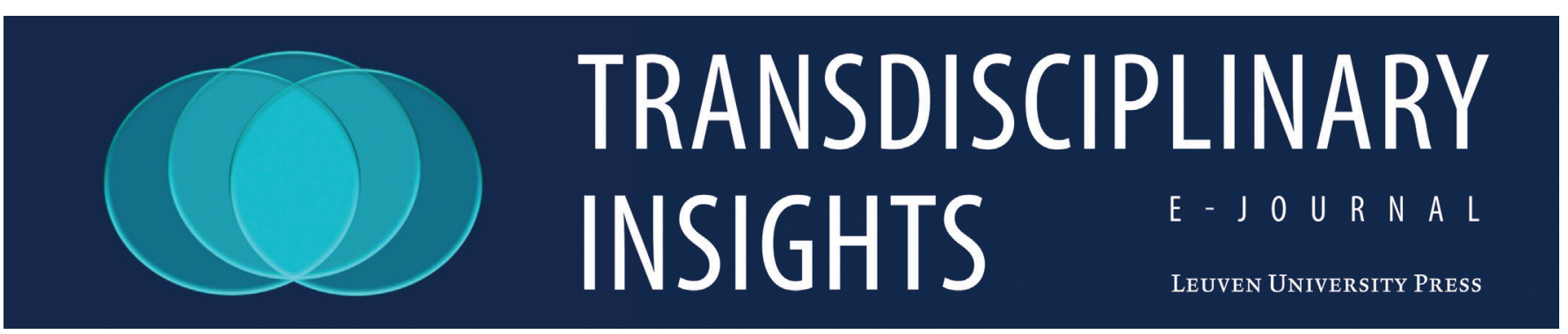

\title{
How Storytelling Can Combat Vaccine Hesitancy: a Transdisciplinary Approach
}

\section{Jacobs Laura ${ }^{1,2 *}$, Kattumana Tarunjose $\mathrm{e}^{1,3 *}$, Konnova Angelina ${ }^{1,4 *}$, Obasa Mojisola ${ }^{1,5 *}$, Smlatic Enisa ${ }^{1,6 *}$, Vandendriessche Valentine $^{1,7 *}$, Voragen Fleur ${ }^{1,8 *}$, Boey Lise ${ }^{9}$, Vandermeulen Corinne ${ }^{10, \$}$}

${ }^{1} \mathrm{KU}$ Leuven - University of Leuven, Honours Program Transdisciplinary Insights, Leuven, Belgium;

${ }^{2} \mathrm{KU}$ Leuven - University of Leuven, Master Student, Pedagogical Sciences, Leuven, Belgium;

${ }^{3} \mathrm{KU}$ Leuven - University of Leuven, Masters Student Research, Philosophy, Leuven, Belgium;

${ }^{4} \mathrm{KU}$ Leuven - University of Leuven, Master Student, Biomedical Sciences, Leuven, Belgium;

${ }^{5}$ KU Leuven - University of Leuven, Master Student, Bioethics, Leuven, Belgium;

${ }^{6} \mathrm{KU}$ Leuven - University of Leuven, Master Student, Pharmaceutical Sciences, Leuven, Belgium;

${ }^{7} \mathrm{KU}$ Leuven - University of Leuven, Master Student, Law, Leuven, Belgium;

${ }^{8} \mathrm{KU}$ Leuven - University of Leuven, Master Student, Medicine, Leuven, Belgium;

${ }^{9} \mathrm{KU}$ Leuven - University of Leuven, PhD Student, Clinical Pharmacology and Pharmacotherapy, Leuven, Belgium;

${ }^{10} \mathrm{KU}$ Leuven - University of Leuven, Department of Pharmaceutical and Pharmacological Sciences, Leuven University Vaccinology Center, Leuven, Belgium;

\begin{abstract}
*These authors contributed equally to the work;
\$Email: corinne.vandermeulen@kuleuven.be
\end{abstract}

\begin{abstract}
The recent decline in vaccination rates across Europe has led to outbreaks of vaccine preventable diseases such as measles. Although there have always been persons opposed to vaccination, in recent years an increasing number of parents are losing confidence in or are being complacent about vaccinating their children. Given the accessibility of information on the internet, parents are actively and independently researching vaccines. They are exposed to negative claims about vaccines that appeal to their emotions and emotional stories tend make parents doubt vaccinations. By contrast, most positive vaccine messages focus on providing information through scientific data which has proven to be ineffective for some hesitant parents.

Vaccine hesitancy can only be understood by looking at it from different perspectives and by exchanging knowledge between multiple fields of study. A transdisciplinary approach, in which individuals with different backgrounds search for solutions together, is necessary to be able to provide one or more solutions to the problem. Therefore, we spent eight months trying to solve part of this wicked
\end{abstract}


problem from a transdisciplinary perspective. Based on literature reviews of different topics within vaccine hesitancy, interviews with hesitant parents, interactions with various stakeholders within and outside academia, and analyses of popular views on social media concerning vaccines, we question the effectiveness of the current pro-vaccine approaches. We also suggest adopting 'storytelling' that incorporates scientific data to inform parents and we argue that narratives are intrinsically persuasive as they are easier to understand and could prove more effective than traditional scientific communication. We expect that this strategy will contribute to the increase in and maintenance of high vaccination coverage rates and stop the circulation and outbreak of vaccine preventable diseases.

\section{Key words}

Vaccine Hesitancy, Anti-vaxx, Vaccine Confidence, Vaccination rates, Vaccination coverage

\section{Challenge Statement}

\section{A way to understand the circumstances that influ- ence refusal of childhood vaccination}

The recent decline in vaccination rates across Europe has led to outbreaks of vaccine preventable diseases such as measles. Although there have always been persons opposed to vaccination, in recent years an increasing number of parents are losing confidence in or are being complacent about vaccinating their children (Dube, et al, 2013, Yaqub, et al, 2014). Given the accessibility of information on the internet, parents are actively and independently researching vaccines. They are exposed to negative claims about vaccines that appeal to their emotions, since this is how the anti-vaxxer community tends to communicate. Emotional stories tend to make parents doubt vaccinations. By contrast, most positive vaccine messaging focuses on providing information through scientific data; this has proven to be ineffective for some hesitant parents (Larson et al, 2010).

As vaccine hesitancy is a wicked problem (Skarbuskis, 2008), it can only be understood by looking at it from different perspectives and by exchanging knowledge between multiple fields of study (Jahn et al, 2012). A transdisciplinary approach, in which individuals with different backgrounds search for solutions together, is necessary to be able to provide one or more solutions to the problem. Therefore, we spent eight months trying to solve part of this wicked problem from a transdisciplinary perspective. Based on literature reviews of different topics within vaccine hesitancy, interviews with hesitant parents, interactions with various stakeholders within and outside academia, and analyses of popular views on social media concerning vaccines, we question the effectiveness of the current provaccine approaches. As reported on the Falling Walls Lab and Facing The Future Symposium, we suggest adopting 'storytelling' that incorporates scientific data to inform parents (Dahlstrom, 2014). We argue that narratives are intrinsically persuasive as they are easier to understand and could prove more effective than traditional scientific communication. This strategy has already been shown to be effective in convincing women to get screened for breast cancer (Keuter, et al, 2010). Addressing parents in different ways, including 'storytelling', might result in more confidence and less complacency. We expect that this strategy will contribute to the increase in and maintenance of high vaccination coverage rates and stop the circulation and outbreak of vaccine preventable diseases.

\section{Supplementary Materials}

1. Original challenge

2. Falling Walls Lab Presentation

3. Facing the Future Symposium Presentation

4. Actor Constellation Game

\section{References}

1. Dahlstrom M. Using narratives and storytelling to communicate science with nonexpert audiences. Proceedings of the National Academy of Sciences. 2014;111(Supplement_4):13614-13620.doi:10.1073/ pnas.1320645111.

2. Dubé E, Laberge C, Guay M, Bramadat P, Roy R, Bettinger J. Vaccine hesitancy. Hum Vaccin Immunother. 2013;9(8):1763-1773. doi:10.4161/hv.24657.

3. Jahn T, Bergmann M, Keil F. Transdisciplinarity: Between mainstreaming and marginalization. Ecological Economics. 2012;79:1-10. doi:10.1016/j. ecolecon.2012.04.017.

4. Kreuter M, Holmes K, Alcaraz K, Kalesan B, Rath S, Richert M, McQueen A, Caito N, Robinson L, Clark E. Comparing narrative and informational videos to increase mammography in low-income African 
American women. Patient Educ Couns. 2010;81:S6S14. doi:10.1016/j.pec.2010.09.008.

5. Larson H, Cooper L, Eskola J, Katz S, Ratzan S. Addressing the vaccine confidence gap. The Lancet. 2011;378(9790):526-535. doi:10.1016/s0140-6736(11) 60678-8.

6. Skaburskis A. The Origin of "Wicked Problems". Planning Theory \& Practice. 2008;9(2):277-280. doi:10.1080/14649350802041654.

7. Yaqub O, Castle-Clarke S, Sevdalis N, Chataway J. Attitudes to vaccination: A critical review. Social Science \& Medicine. 2014;112:1-11. doi:10.1016/j. socscimed.2014.04.018.

\section{Reading List}

1. Amin A, Bednarczyk R, Ray C, Melchiori K, Graham J, Huntsinger J, Omer S. Association of moral values with vaccine hesitancy. Nat Hum Behav. 2017;1(12): 873-880. doi:10.1038/s41562-017-0256-5.

2. Browne M, Thomson P, Rockloff M, Pennycook G. Going against the Herd: Psychological and Cultural Factors Underlying the 'Vaccination Confidence Gap'. PLoS ONE. 2015;10(9):e0132562. doi:10.1371/journal. pone. 0132562 .

3. Butler R, MacDonald N. Diagnosing the determinants of vaccine hesitancy in specific subgroups: The Guide to Tailoring Immunization Programmes (TIP). Vaccine. 2015;33(34):4176-4179. doi:10.1016/j.vaccine.2015. 04.038 .

4. Corcoran B, Clarke A, Barrett T. Rapid response to HPV vaccination crisis in Ireland. The Lancet. 2018;391(10135):2103. doi:10.1016/s0140-6736(18) 30854-7.

5. Dahlstrom M, Ho S. Ethical Considerations of Using Narrative to Communicate Science. Sci Commun. 2012;34(5):592-617.doi:10.1177/1075547012454597.

6. Dahlstrom M. Using narratives and storytelling to communicate science with nonexpert audiences. Proceedings of the National Academy of Sciences. 2014;111(Supplement_4):13614-13620. doi:10.1073/ pnas.1320645111.

7. De keersmaecker J, Roets A. 'Fake news': Incorrect, but hard to correct. The role of cognitive ability on the impact of false information on social impressions. Intelligence. 2017;65:107-110. doi:10.1016/j.intell. 2017.10.005.

8. Donzelli G, Palomba G, Federigi I, Aquino F, Cioni L, Verani M, Carducci A, Lopalco P. Misinformation on vaccination: $A$ quantitative analysis of YouTube videos. Hum Vaccin Immunother. 2018:1-6. doi:10.1 080/21645515.2018.1454572.
9. Dredze M, Broniatowski D, Smith M, Hilyard K. Understanding Vaccine Refusal. Am J Prev Med. 2016;50(4):550-552. doi:10.1016/j.amepre.2015. 10.002 .

10. Dubé E, Laberge C, Guay M, Bramadat P, Roy R, Bettinger J. Vaccine hesitancy. Hum Vaccin Immunother. 2013;9(8):1763-1773. doi:10.4161/hv.24657.

11. Dubé E, Vivion M, MacDonald N. Vaccine hesitancy, vaccine refusal and the anti-vaccine movement: influence, impact and implications. Expert Rev Vaccines. 2014;14(1):99-117. doi:10.1586/14760584.2015.964 212.

12. Edwards K, Hackell J. Countering Vaccine Hesitancy. Pediatrics. 2016;138(3):e20162146-e20162146. doi: 10.1542/peds.2016-2146.

13. Fadda M, Galimberti E, Fiordelli M, Romanò L, Zanetti A, Schulz P. Effectiveness of a smartphone app to increase parents' knowledge and empowerment in the MMR vaccination decision: A randomized controlled trial. Hum Vaccin Immunother. 2017;13(11): 2512-2521. doi:10.1080/21645515.2017.1360456.

14. Favin $M$, Steinglass $R$, Fields $R$, Banerjee $K$, Sawhney M. Why children are not vaccinated: a review of the grey literature. Int Health. 2012;4(4):229238. doi:10.1016/j.inhe.2012.07.004.

15. Fokoun C. Strategies implemented to address vaccine hesitancy in France: a review article. Hum Vaccin Immunother. 2018:1-41. doi:10.1080/216455 15.2018 .1458807$.

16. Gowda C, Dempsey A. The rise (and fall?) of parental vaccine hesitancy. Hum Vaccin Immunother. 2013; 9(8):1755-1762. doi:10.4161/hv.25085.

17. Haverkate M, D’Ancona F, Giambi C, Johansen K, Lopalco P, Cozza V, Appelgren E, on behalf of the VENICE project gat C. Mandatory and recommended vaccination in the EU, Iceland and Norway: results of the VENICE 2010 survey on the ways of implementing national vaccination programmes. Eurosurveillance. 2012;17(22). doi:10.2807/ese.17.22.20183-en.

18. Hendrix K, Sturm L, Zimet G, Meslin E. Ethics and Childhood Vaccination Policy in the United States. Am J Public Health. 2016;106(2):273-278. doi: 10.2105/ajph.2015.302952.

19. Hinyard L, Kreuter M. Using Narrative Communication as a Tool for Health Behavior Change: A Conceptual, Theoretical, and Empirical Overview. Health Education \& Behavior. 2007;34(5):777-792. doi: 10.1177/1090198106291963.

20. Kolodziejski L. Harms of Hedging in Scientific Discourse: Andrew Wakefield and the Origins of the Autism Vaccine Controversy. Technical Communication Quarterly. 2014;23(3):165-183. doi:10.1080/10572252 .2013.816487. 
21. Kreuter M, Holmes K, Alcaraz K, Kalesan B, Rath S, Richert M, McQueen A, Caito N, Robinson L, Clark E. Comparing narrative and informational videos to increase mammography in low-income African American women. Patient Educ Couns. 2010;81: S6-S14. doi:10.1016/j.pec.2010.09.008.

22. Larson H, Cooper L, Eskola J, Katz S, Ratzan S. Addressing the vaccine confidence gap. The Lancet. 2011;378(9790):526-535. doi:10.1016/s0140-6736 (11)60678-8.

23. Larson H, Jarrett C, Eckersberger E, Smith D, Paterson $P$. Understanding vaccine hesitancy around vaccines and vaccination from a global perspective: A systematic review of published literature, 2007-2012. Vaccine. 2014;32(19):2150-2159. doi:10.1016/j.vaccine. 2014.01.081.

24. Larson H, Clarke R, Jarrett C, Eckersberger E, Levine Z, Schulz W, Paterson P. Measuring trust in vaccination: A systematic review. Hum Vaccin Immunother. 2018:1-11. doi:10.1080/21645515.2018.1459252.

25. Lawler E. Effectiveness of vaccination recommendations versus mandates: Evidence from the hepatitis $A$ vaccine. J Health Econ. 2017;52:45-62. doi:10.1016/j. jhealeco.2017.01.002.

26. Nisbet M, Scheufele D. What's next for science communication? Promising directions and lingering distractions. Am J Bot. 2009;96(10):1767-1778. doi: 10.3732/ajb.0900041.

27. Paterson P, Meurice F, Stanberry L, Glismann S, Rosenthal S, Larson H. Vaccine hesitancy and healthcare providers. Vaccine. 2016;34(52):6700-6706. doi:10.1016/j.vaccine.2016.10.042.

28. Paulussen T, Hoekstra F, Lanting C, Buijs G, Hirasing R. Determinants of Dutch parents' decisions to vaccinate their child. Vaccine. 2006;24(5):644-651. doi: 10.1016/j.vaccine.2005.08.053.

29. Peretti-Watel P, Ward J, Schulz W, Verger P, Larson H. Vaccine Hesitancy: Clarifying a Theoretical Framework for an Ambiguous Notion. PLoS Curr. 2015. doi:10.1371/currents.outbreaks.6844c80ff9f 5b273f34c91f71b7fc289.

30. Périnet S, Kiely M, De Serres G, Gilbert N. Delayed measles vaccination of toddlers in Canada: Associated socio-demographic factors and parental knowledge, attitudes and beliefs. Hum Vaccin Immunother. 2018;14(4):868-874. doi:10.1080/21645515.2017.14 12899.

31. Pohl C, Krütli P, Stauffacher M. Ten Reflective Steps for Rendering Research Societally Relevant. GAIA Ecological Perspectives for Science and Society. 2017;26(1):43-51. doi:10.14512/gaia.26.1.10.

32. Sadaf A, Richards J, Glanz J, Salmon D, Omer S. A systematic review of interventions for reducing parental vaccine refusal and vaccine hesitancy. Vaccine. 2013;31(40):4293-4304. doi:10.1016/j. vaccine.2013.07.013.

33. Salmon D, Dudley M, Glanz J, Omer S. Vaccine hesitancy. Vaccine. 2015;33:D66-D71. doi:10.1016/j. vaccine.2015.09.035.

34. Schmid P, MacDonald N, Habersaat K, Butler R. Commentary to: How to respond to vocal vaccine deniers in public. Vaccine. 2018;36(2):196-198. doi:10.1016/j.vaccine.2016.09.065.

35. Yaqub O, Castle-Clarke S, Sevdalis N, Chataway J. Attitudes to vaccination: A critical review. Social Science \& Medicine. 2014;112:1-11. doi:10.1016/j. socscimed.2014.04.018.

\section{Relevant Websites}

1. Shot By Shot. Shot By Shot. 2018. Available at: http:// www.shotbyshot.org/. Accessed July 3, 2018.

2. CDC. Centers for Disease Control and Prevention. 2018. Available at: https://www.cdc.gov/. Accessed July 3, 2018.

3. WHO | World Health Organization. Whoint. 2018. Available at: http://www.who.int/. Accessed July 3, 2018.

4. Child's death from measles caught from unvaccinated brother reignites debate in Italy. euronews. 2018. Available at: http://www.euronews.com/2017/06/23/ childs-death-from-measles-caught-from-unvaccinatedbrother-reignites-debate-in. Accessed July 3, 2018.

5. Why I wish my daughter had been vaccinated / Sophie Heawood. the Guardian. 2018. Available at: https:// www.theguardian.com/commentisfree/2013/apr/24/ wish-my-daughter-vaccinated. Accessed July 3, 2018.

6. A Good Story Is Always Far More Persuasive Than Facts and Figures. Inccom. 2018. Available at: https:// www.inc.com/james-sudakow/why-a-good-story-isfar-more-persuasive-than-facts.html. Accessed July 3, 2018.

7. The Science of Storytelling: Why Telling a Story is the Most Powerful Way to Activate Our Brains. Lifehackercom. 2018. Available at: https://lifehacker. com/5965703/the-science-of-storytelling-why-tellinga-story-is-the-most-powerful-way-to-activate-ourbrains. Accessed July 3, 2018.

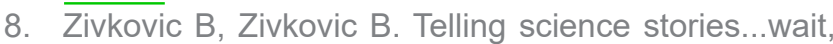
what's a "story"?. Scientific American Blog Network. 2018. Available at: https://blogs.scientificamerican. com/a-blog-around-the-clock/httpblogsscientificamericancoma-blog-around-the-clock20110713 telling-science-stories-wait-whats-a-story/. Accessed July 3, 2018. 


\section{Supplement 1: ORIGINAL CHALLENGE}

\section{NAME: A WAY TO UNDERSTAND THE CIRCUMSTANCES THAT INFLUENCE REFUSAL OF CHILD- HOOD VACCINATION.}

\section{Background of the challenge:}

Apart from running water and hygiene, vaccines are the best preventive medical invention/intervention that have worldwide impacted significantly on morbidity and mortality and their effect can hardly be overestimated. By using vaccines systematically and globally through organized vaccination programs, about 2-3 million deaths are averted annually (WHO). The advantage of vaccines is not only that they are able to provide an individual with protection against disease, but a vaccinated person can, for most vaccines, be no longer infected and will thus stop transmission of the infectious pathogen. This phenomenon made eradication of smallpox possible as well as the elimination of many vaccine-preventable diseases (e.g. polio, diphtheria, measles, rubella, ...) in countries with a high vaccination coverage. By organizing vaccination programs, where $>90-95 \%$ of the population is vaccinated, spreading of the disease can be stopped and the most vulnerable children and adults, who cannot be vaccinated or do not respond to vaccination, can also be protected. This is called herd or population immunity.

Despite the overwhelming scientific evidence of the positive effect of vaccination and of herd immunity, over the last decade vaccines have been the victims of their own success. The current generation of new parents is no longer familiar with the severity and complications of vaccine-preventable infectious diseases and parents are increasingly focused on (alleged) side effects of vaccines. This phenomenon, called vaccine hesitancy, has led to a lowering of confidence in the effects of vaccination and an increasing proportion of parents doubting and delaying vaccination, or even refusing to have their child vaccinated. Even though it is the individual choice of parents not to immunize their child, it should be placed in a broader societal context. Especially, over the internet and through social networks fake news on vaccines is spreading with lightning speed. Shares, likes, and tweets of emotional witnesses about the alleged side effects of vaccines are spread more easily than solid scientific evidence. Parents also tend to click more on negative news when looking for information on vaccines on the internet. Additionally, search engines have features which are more advantageous for negative vaccine messages as inputs of searches are already pre-populated by search strings that are used more often. As such the anti-vaccine movement is helped by technology and is increasing vaccine hesitancy in parents. As a result more parents refuse to have their children vaccinated or postpone essential vaccination to a later, mostly undefined, age.

Unfortunately, this hesitancy has led to a decrease in vaccination coverage in different countries and has given rise to new epidemics of vaccine preventable diseases which we thought had been eliminated, such as measles. This means that unprotected and often vulnerable children get ill and suffer again from complications of infectious diseases which had almost disappeared.

Even though many initiatives have already been taken to identify factors which influence vaccine hesitancy (e.g. vaccine confidence project), and many initiatives are taken to increase vaccine confidence, new ways of tackling this issue would still be most welcome. It is important that this high wave of vaccine hesitancy is somehow stopped before our countries are flooded again with vaccine-preventable diseases.

\section{Possible partners, experts and/or other stakeholders to involve in this challenge:}

1. People knowledgeable about social media

2. People who have dealt with crises regarding infectious diseases or vaccine crises

3. WHO Europe

4. Other academia developing tools to increase vaccination coverage

5. People who have suffered from vaccine-preventable diseases 


\title{
Supplement 2: FALLING WALLS LAB PRESENTATION
}

Video:

1. Breaking the Wall of Vaccine Hesitancy | Falling Walls Lab Leuven. YouTube. 2018. Available at: https://www. youtube.com/watch?v=cma2WwHSKiM. Accessed July 3, 2018.

2. Another version is here.

\section{BREAKING THE WALL OF VACCINE HESITANCY}

\author{
TARUN JOSE KATTUMANA \\ INDIA
}

KU LEUVEN

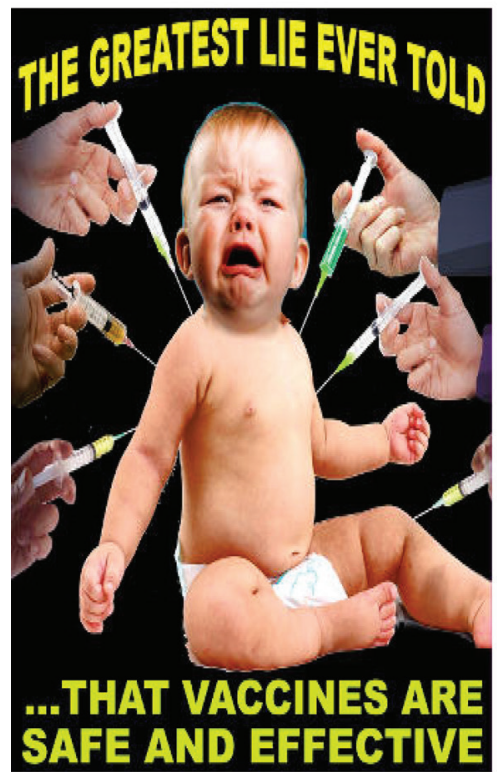

Vaccines Save Lives

Worldwide

VACCINES HELP CHILDREN

Grow Up to Achieve Their Full Potentiol

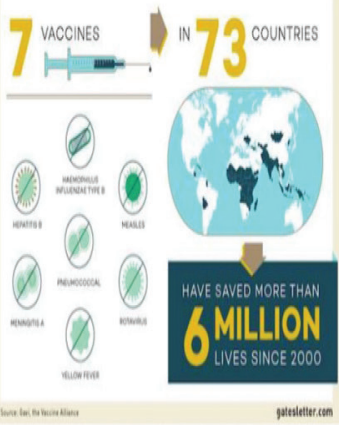




\section{Pro-Vaccine Messages need to use Personal Stories}

\section{Summary:}

Our project was selected to participate in the KU Leuven chapter of the Falling Walls Lab, an international forum for researchers to present their ideas to both a wider public audience and a panel of specialist judges. We argued for a better understanding of vaccine hesitant parents who refused to vaccinate their children fearing the unverified side-effects vaccines might have. This was important given the return of vaccine preventable diseases as seen in the case of 35 deaths and a three-fold increase in measles cases across Europe.

Our presentation focused on the differences between pro-vaccine and anti-vaccine messaging. While pro-vaccine messages focused on facts and figures; anti-vaccine messages relied on narrative structures that had tremendous emotional appeal and talked to the fears and anxieties that parents have. This difference contributed to the ineffectiveness of pro-vaccine messaging. This in turn contributed towards reduced vaccine coverage in several European states. To counter this trend, we argued that pro-vaccine messages need to use 'storytelling' and personal narratives to convey facts effectively in a manner that spoke to the concerns of hesitant parents. We had had the opportunity to present a version of this presentation at the REGA Institute, KU Leuven.

Text:

Let me tell you a story. A story about William. ${ }^{1}$ William was born in 2017, but also died that very same year of measles. He got infected by the neighbour's son whose parents were against vaccination.

A tragedy like this could easily have been prevented by vaccination.

This is not an isolated incident. Last year we saw 35 deaths and a 3-fold increase in measles cases across Europe.

But why are these parents hesitant?

Parents care about the health of their children. This makes them vulnerable to anti-vaccine messages. These messages repeat myths that vaccines would cause side-effects like autism. While most of us would laugh this off as crazy conspiracy theory, we forget that people are no longer familiar with deadly diseases because vaccines prevent them from happening. Thus, vaccines have become a victim of their own success. 
On the other hand, parents keep hearing about bad things vaccine do to children.

So a hesitant parent is faced with a very difficult choice.

1. Vaccinating for a disease that does not seems to exist anymore

2. Not vaccinating and preventing the autism side-effect.

Most pro-vaccine messages try to combat these fears with facts, graphs and numbers. But this does not seem to work. One of the primary reasons for this is the increasing distrust in the government, pharmaceutical companies and the language of science. Just as biblical evidence would not convince an atheist, scientific evidence will not convince a sceptic of science.

We need to change the way we communicate with hesitant parents.

Pro-vaccine messages need to rely less on brute facts and more on personal stories if we want to convince parents that they need to vaccinate.

Coming back to William. A story like this speaks about the concerns that parents have. It makes its point without overly relying on facts, graphs or numbers. It is a story that parents can identify with.

And this is my most crucial message to you.

Vaccines work best if a significant number of us are vaccinated. Otherwise, tragedies like William's, where diseases spread through people who are not vaccinated, is only more likely to happen.

Vaccines are a good and safe solution but they need to be implemented widely.

And we can only effectively implement them if we can take away the fears and anxieties that hesitant parents have.

So when you encounter a hesitant parent, do not just give them facts and figures. Do not just say science is right. Tell them a story because stories speak to the heart.

${ }^{1}$ The name has been changed 


\section{Supplement 3: FACING THE FUTURE SYMPOSIUM PRESENTATION}

\section{Video: here}

Text:

Vaccines are considered to be one of the discoveries with the highest impact on public health. Currently, there are vaccines available against 26 different diseases. Every year they prevent approximately 2-3 million deaths. However, by increasing immunization coverage an additional 1.5 million deaths could be prevented. In addition, vaccines limit the spread of antibiotic resistance, which is an important healthcare concern worldwide nowadays.

But today, the rise of vaccine hesitancy is causing a rapid decrease in vaccine coverage, resulting in a higher risk of epidemics of vaccine preventable diseases, such as measles, polio, and whooping cough. Last year alone, we saw a 3-fold increase in measles cases across Europe.

To further illustrate the impact vaccine hesitancy can have, let me tell you a story about Alessandro. ${ }^{1}$ Alessandro was a six-year-old Italian boy suffering from leukemia who died last year from measles complications. He caught measles from his older sibling, who was not vaccinated. Alessandro's death could have been avoided if everyone in his community had been vaccinated.

Imagine now, you are a parent and need to decide whether or not you would vaccinate your child. Which of these two messages would you find more convincing? A WHO poster or Alessandro's story?

Let us know by voting and we will have a look at the end of this presentation.

There is not just one reason why parents are hesitant to vaccinate their children.

In fact, vaccine hesitancy is such a serious problem that the reasons for it were categorised by the WHO into three groups:

1. Convenience: the decision to vaccinate is influenced by vaccine accessibility.

2. Complacency: this is when people think vaccination is no longer necessary.

3. Confidence: this is about the lack of trust in vaccines.

We focused on confidence and complacency in early childhood vaccinations, such as measles, mumps, rubella (also called MMR), mainly because confidence and complacency are important issues in Belgium.

We began with a literature review. There turned out to be a lot of different factors or reasons for vaccine hesitancy. For example, no longer being familiar with deadly vaccine-preventable diseases and distrust in government, Big Pharma and science. But this is only the tip of the iceberg. There are so many other reasons. Like concerns about vaccine safety and side effects, the use of animals in vaccine testing and production, and the ineffectiveness of pro-vaccine messaging.

We also conducted interviews with key stakeholders, including experts in social sciences, filmmaking, virology, public health, as well as a WHO Europe representative. We would like to thank all of them for their contributions.

After talking to these stakeholders we have identified social media as a powerful tool in propagating anti-vaccine messages. Search engines play a big role in this problem. They are easily accessible. However, the algorithms that deliver the search results standing behind them are unknown. What is known is that the search results are filtered on

\footnotetext{
${ }^{1}$ The name has been changed
} 
popularity and previous search history, but are not based on the reliability of the content. For example, parents that look for 'vaccines' get on a rollercoaster of negative information, and cannot make a well informed decision.

Anti-vaccine communities are popular and widespread on the Internet. They are accessible and open to communication. They are dynamic and up to date, and able to catch one's attention. Therefore they are attractive to hesitant parents. And these anti-vaccine communities use emotional stories to convey their message.

We have compared pro-vaccine and anti-vaccine strategies using the most popular YouTube videos related to vaccination.

Analysis of different types of videos revealed that most of the anti-vaccine videos are presented in a format that can include 'storytelling', such as home-made videos, collages, interviews, public speeches and YouTube or TV shows. In contrast, pro-vaccine videos were presented in a wider range of different formats, most of which were not suitable for emotional stories.

Furthermore, we also conducted a couple of interviews with parents hesitant about vaccinations.

For example, a parent told us: 'I talked to doctors .. but I also spoke to a Somali woman, because I know that in their culture they often don't vaccinate due to religious viewpoints. What she told me was worth thinking about. She told me about her uncle who had 6 children. Unfortunately, he didn't have them anymore, they all died of measles. .. It shows how deadly measles can be and that vaccinating does work. ...'

We asked her: 'What had the biggest impact on your decision, the personal story or what the doctors said?'

And she replied: 'To be honest, the personal story. For me as a layman a personal story has more impact.'

Interview analysis supported our hypothesis about 'storytelling' being more convincing than official reports.

In fact, personal stories have already been shown to be an effective strategy with respect to other health related issues, such as convincing women to get tested for breast cancer.

We have identified three promising ways to tell personal stories about vaccines:

1. Vaccines as part of the 'green' lifestyle

2. Protection for immunocompromised patients

3. Consequences of vaccine-preventable diseases

However, we have a very heterogeneous group of hesitant people, so it is crucial that a strategy of 'storytelling' is well adapted to a particular subgroup.

There is a spectrum of attitudes to vaccinations, and we want to focus on only hesitant people, since anti-vaccine people are very hard to convince, because they would stand up for their beliefs as if they were a religion.

Our future plans would include making videos of these personal stories that could be shared through social media. A pilot study with them would help us better understand which factors would be more efficient, for example, positive or negative emotional stories. 


\section{Supplement 4: ACTOR CONSTELLATION GAME}

\section{Description:}

Actor constellation | Co-producing Knowledge. Naturalsciencesch. 2018. Available at: https://naturalsciences.ch/ topics/co-producing_knowledge/methods/actor_constellation_final_. Accessed July 3, 2018.

\section{Result:}

1. 1st Actor Constellation Game is attached

2. 2nd Actor Constellation Game is attached

\section{$1^{\text {st }}$ Actor of Constellation: Vaccine Hesitancy}

Transdisciplinary Insights - KU Leuven

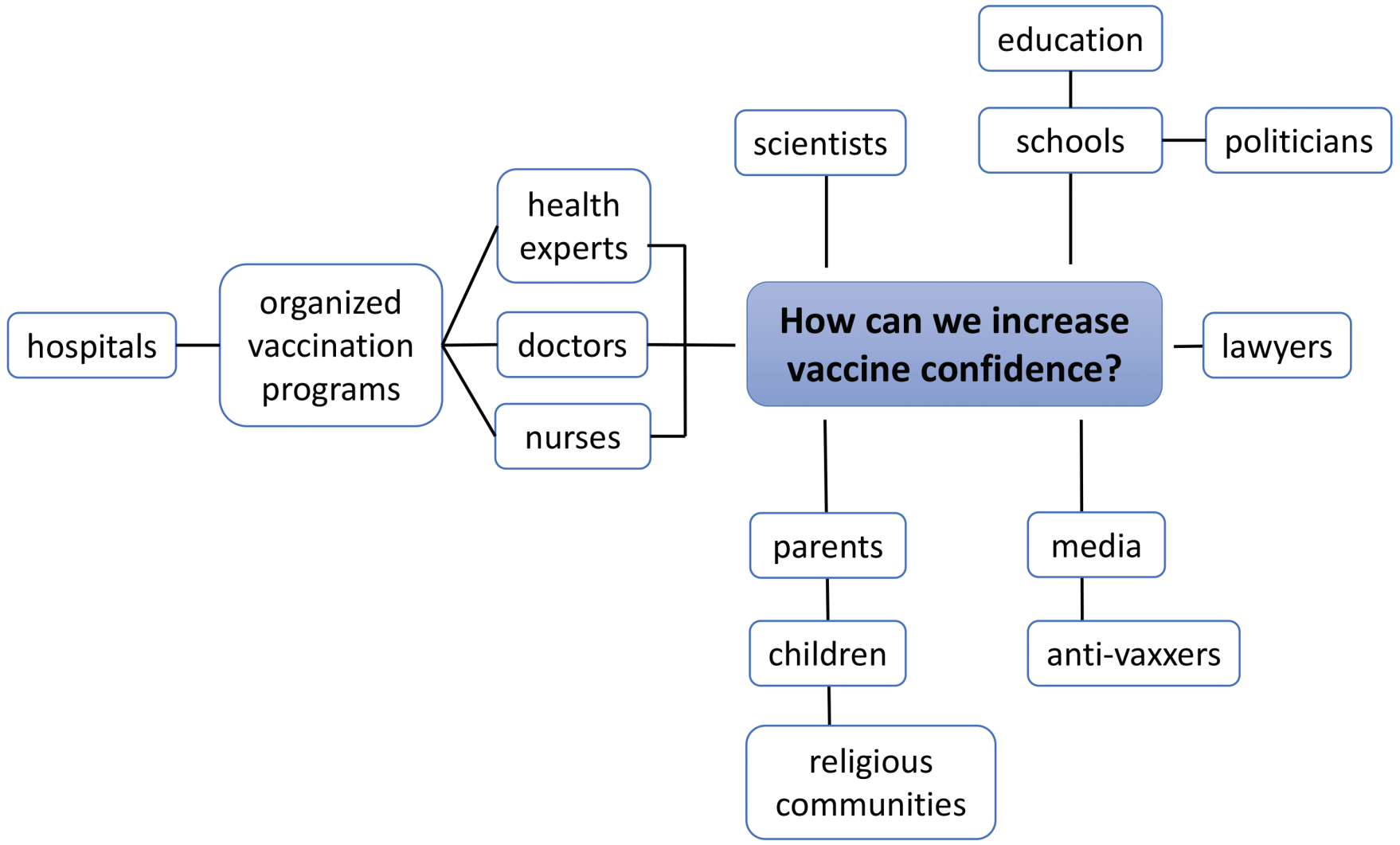




\section{$2^{\text {nd }}$ Actor of Constellation: Vaccine Hesitancy}

\section{Transdisciplinary Insights - KU Leuven}

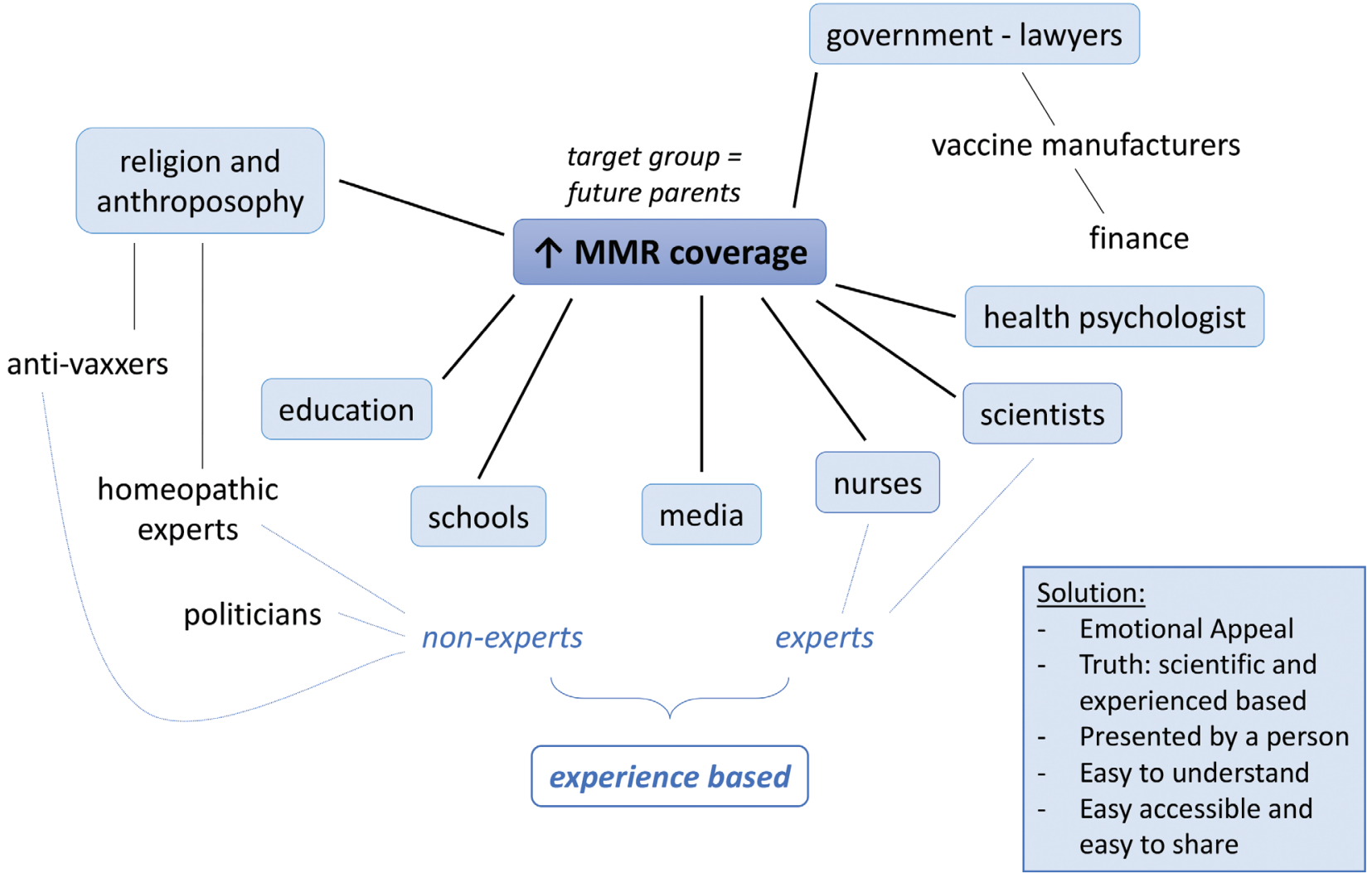

